\title{
Heat Reclaim from Air Conditioning System with Internally Submerged and Externally Wound Condenser Tubes
}

\author{
K. S. Ong ${ }^{1}$ \\ ${ }^{1}$ School of Engineering, Monash University Sunway Campus, Kuala Lumpur, Malaysia \\ Correspondence: K. S. Ong, School of Engineering, Monash University Sunway Campus, Jalan Lagoon Selatan, \\ 46150 Bandar Sunway, Malaysia. Tel: 60-3-5514-6000. E-mail: Ong.Kok.Seng@monash.edu
}

Received: January 11, 2012

Accepted: March 8, 2012 Published: May 1, 2012

doi:10.5539/emr.v1n1p101

URL: http://dx.doi.org/10.5539/emr.v1n1p101

\begin{abstract}
Desuperheaters have been in common use for many years to recover heat from the superheated refrigerant of the vapour-compression refrigeration cycle to provide hot water for domestic consumption. Concentric pipe desuperheaters provided with a double-wall construction as a safety precaution are directly submerged in the water tank or indirectly with external recirculating pumps. They are more expensive than bare tube heat exchangers that are directly submerged in the storage tank. It is possible to wrap the condenser coil around the tank with loss of performance. An experimental investigation was conducted to compare the performance of an air conditioning system with these different condensers. The first condenser had a coil submerged in the hot water storage tank while the other had a coil wound round it. The internal coil was found to be more efficient.
\end{abstract}

Keywords: heat pump, heat reclaim, heat recovery, desuperheating, internal coil, external coil

\section{Introduction}

Desuperheaters have been employed for many years to recover heat from the superheated refrigerant in the vapour-compression refrigeration cycle. An actual refrigeration cycle with a conventional air-cooled condenser and a water-cooled desuperheater is shown schematically in Fig. 1. Superheated vapor from the evaporator (1) is compressed to a superheat temperature in the compressor (2). The superheated vapor is then first cooled by the desuperheater to an intermediate stage (3) before it is finally condensed to a saturated liquid (4) by the air-cooled condenser. Sub-cooling takes the liquid to a sub-cooled state (5). It then expands in the expansion valve to a mixture state ( 6 or 7$)$. Cooling takes place in the evaporator and the mixture is brought to a saturated vapour state (8). In actual cycles, pressure drops occur along the liquid and vapour lines. The desuperheater could be in the form of an internally immersed coil-in-tank heat exchanger as illustrated in Fig. 1(a) or the heat exchanger coil could be wound externally around the tank. A concentric double-pipe water-cooled heat exchanger with water circulating between it and the hot water storage tank could also be employed. In general, the performance of the system would depend upon the design of the desuperheating coil. The p-h diagram of the cycle is shown in Fig. 1(b). During desuperheating $(2-3)$ water is heated by the refrigerant as it condenses and the hot water is stored in the hot water storage tank. Thus we have both heating and cooling simultaneously from a single machine. In this paper, we shall term the process as heat reclaim.

The incorporation of the water cooled condenser in an otherwise conventional vapor compression refrigerating system results in energy savings and enhances the cooling capacity of the air conditioning system. Bong, Hawlader and Mahmood (1988) presented a computer model to show that energy recovery improved the performance of the air conditioner in the tropics. Valentine and Goldschmidt (1989) presented an effectiveness NTU model with a concentric pipe desuperheater. Ying (1989) concluded that if the capillary tube of a room air conditioner is replaced by a thermostatic expansion valve the unit can be used for hot water heating without losing its cooling capacity. Cook (1990) presented sizing requirements for concentric pipe desuperheaters. Toh and Chan (1993) used the concentric pipe desuperheater but relied on thermosyphon recirculation instead of the water pump. Lee and Jones (1996) tested a concentric pipe desuperheater coupled to a residential hot water storage system. An analytical model of the residential desuperheater was developed by Lee and Jones (1997). Mei, Chen, Domitrivic, Kilpatrick and Carter (2003) studied the performance of a heat pump water system with 
the condenser coil submerged in the storage tank obviating the need for a water recirculating pump. They used two basically different types of coils, the bayonet style and the U-tube style and found that the latter performed better in terms of heating capacity and coefficient of performance (COP). Jie, Chow, Pei and He (2003) introduced a novel multi-function air conditioner with an additional condenser coil submerged in water. By switching between isolating valves, the system could be used for a combination of space cooling and heating and water heating. A recent review of heat pump water heating systems is given by Hepbasli and Kalinci (2009).

Concentric pipe desuperheaters are normally always employed in the US and other Western countries. These exchangers are usually provided with a double-wall construction as a safety precaution should the refrigerant piping develop a leak. They are directly submerged in the water storage tank or indirectly with external recirculating pumps. In either case, they are more expensive than bare tube heat exchangers that are directly submerged in the hot water storage tank. In some countries, legislation may prohibit the use of the latter. One way to overcome this is to wrap the condenser coil around the outside diameter of the tank. The thermal performance of this indirect system would obviously be affected. To date there has been no reported data to compare the heat reclaim effectiveness of using the internally immersed or the externally wound coil system.

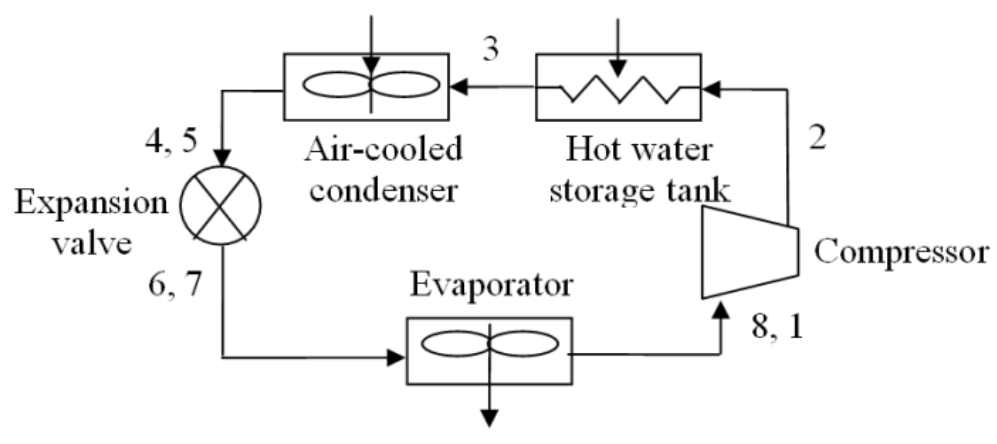

(a) Schematic of vapour-compression cycle

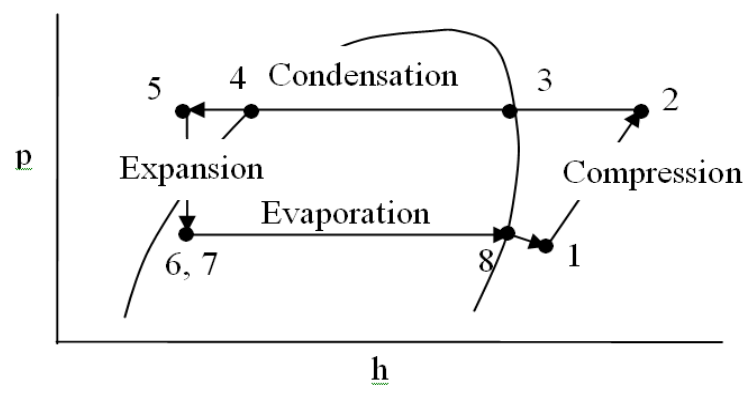

(b) P-h diagram of vapour-compression cycle

Figure 1. The ideal vapour-compression cycle with heat reclaim

\section{Objective}

The objective of the present investigation is to compare the performance of a heat reclaim system from a conventional room air conditioning system using internally immersed and externally wound condenser coils.

\section{Experimental Investigation}

A conventional R-22 split unit air conditioner was installed with the evaporating (indoor) unit located inside the laboratory and the air-cooled condensing (outdoor) unit mounted outdoors. Two heat reclaim stainless steel hot water storage tanks were fabricated and installed vertically above the condensing unit, Fig. 2. Switchover valves enabled either one of the two tanks to be connected in series with the conventional air condenser. The tank with the internal coil had an internal diameter of $320 \mathrm{~mm}$ and was $550 \mathrm{~mm}$ long giving an internal volume of 0.044 $\mathrm{m}^{3}$. It was insulated with $50 \mathrm{~mm}$ thick polyurethane insulation foamed in-situ and protected externally with a stainless steel outer casing. The tank with the external coil had an internal diameter of $420 \mathrm{~mm}$ internal diameter and was $533 \mathrm{~mm}$ long giving an internal volume of $0.074 \mathrm{~m}^{3}$. It was also insulated with $50 \mathrm{~mm}$ thick 
polyurethane insulation and provided with a stucco-embossed aluminium outer casing. The tank with the internal coil was fitted internally with a $3 \mathrm{~m}$ long $\times 9.5 \mathrm{~mm} \mathrm{I} / \mathrm{D} \times 10 \mathrm{~mm} \mathrm{O} / \mathrm{D}$ copper tube. The other tank had a $4 \mathrm{~m}$ long $\times 9.5 \mathrm{~mm} \mathrm{I/D} \mathrm{\times} 10 \mathrm{~mm}$ O/D copper tube wound around on the outside of the tank. The air conditioner was a commercially available $1 \mathrm{hp}$ York split unit air conditioner fitted with a thermostatic expansion valve.

Experiments were carried out to determine the performance under three operating test conditions; viz., (a) baseline case without heat reclaim, (b) heat reclaim with internally immersed coil and (c) heat reclaim with externally wound coil. Indoor room and outdoor ambient conditions were not controlled. Experimental results were obtained by repeating the tests in order to obtain test data within the range of test conditions as indicated in Table 1. A schematic diagram of the experimental set-up is shown in Fig. 3. Two-way valves were employed to switch the refrigerant flow over from the baseline case to the other two heat reclaim cases. The hot water storage tanks were located before the standard air-cooled condenser in order to reclaim heat by desuperheating the hot vapour after compression and before condensation. The water temperature distribution inside the tanks were measured by inserting 3 type $\mathrm{T}$ thermocouples $\left(\mathrm{Cu}\right.$-Constantan with an accuracy of $\pm 0.5^{\circ} \mathrm{C}$ ) into the water tanks through the vent pipes. Refrigerant pressures were measured with $100 \mathrm{~mm}$ face diameter pressure gauges (accuracy of $\pm 2 \%$ full scale) at the location shown. Refrigerant mass flow rate was measured with a Yokogawa volumetric flowmeter. Power input to the compressor was measured with a Feedback electronic wattmeter. Experimental data were taken at hourly intervals for about 8 hours.

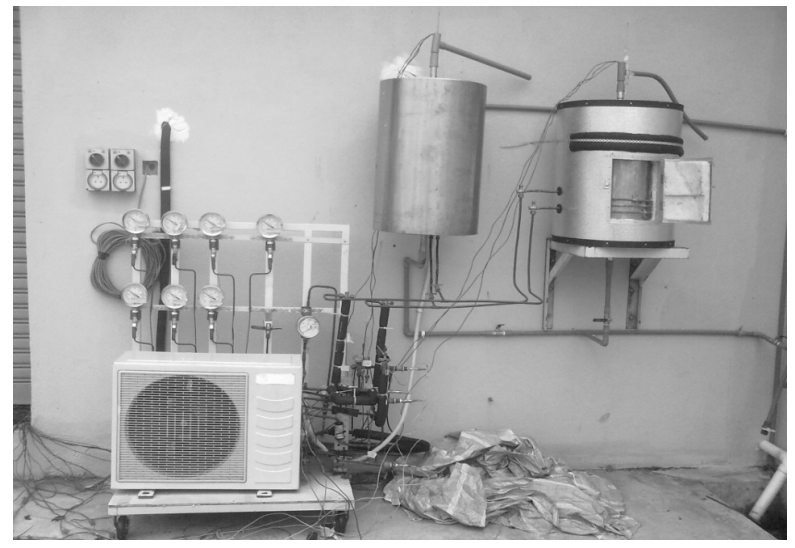

Figure 2. Photograph of condensing outdoor units

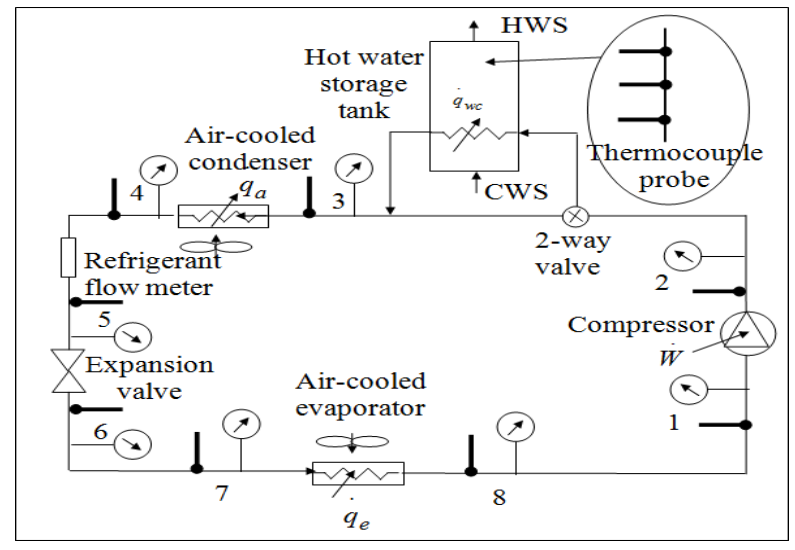

Figure 3. Schematic diagram of experimental air conditioning unit with heat reclaim

\section{Mathematical analysis}

\subsection{Baseline Case}

Heat absorbed at the evaporator is calculated from

$$
\dot{q}_{e}=\dot{m}\left(h_{8}-h_{7}\right)
$$

and heat rejected at the air-cooled condenser from

$$
\dot{q}_{c}=\dot{m}\left(h_{2}-h_{4}\right)
$$

Compressor power input is calculated from

$$
P_{\text {calc }}=\dot{m}\left(h_{2}-h_{1}\right)
$$

The ratio of calculated/measured compressor power is calculated from

$$
\gamma_{1}=\frac{P_{c a l c}}{P}
$$

The cooling coefficient of performance is given by 


$$
C O P_{r}=\frac{\dot{q}}{P}
$$

and the heating coefficient of performance by

$$
C O P_{h p}=\frac{\dot{q_{c}}}{P}
$$

\subsection{Heat Reclaim}

Heat rejected at the air-cooled condenser is calculated from

$$
\dot{q}_{a}=\dot{m}\left(h_{3}-h_{4}\right)
$$

and the heat rejected at water-cooled condenser from

$$
\dot{q}_{w c}=\dot{m}\left(h_{2}-h_{3}\right)
$$

Total heat rejected is given by

$$
\dot{q}_{t}=\dot{m}\left(h_{2}-h_{4}\right)
$$

The ratio of heat rejected at water-cooled condenser to total heat rejected is calculated from

$$
\gamma_{2}=\frac{\dot{q}_{w c}}{\dot{q}_{t}}
$$

\section{Discussion of Results}

\subsection{Mean Water Temperature}

Figure 4 shows a typical water temperature distribution inside one of the storage tanks at the end of 8 hours. The temperatures were observed to be very nearly uniform in the upper portion of the tank. The mean water temperatures were calculated from the arithmetic mean of the probe temperatures. Bulk mean temperatures were obtained by determining the area under the temperature-height distribution curves at the various times shown. Differences of less than $0.5^{\circ} \mathrm{C}$ were observed between the bulk mean and the arithmetic mean temperatures.

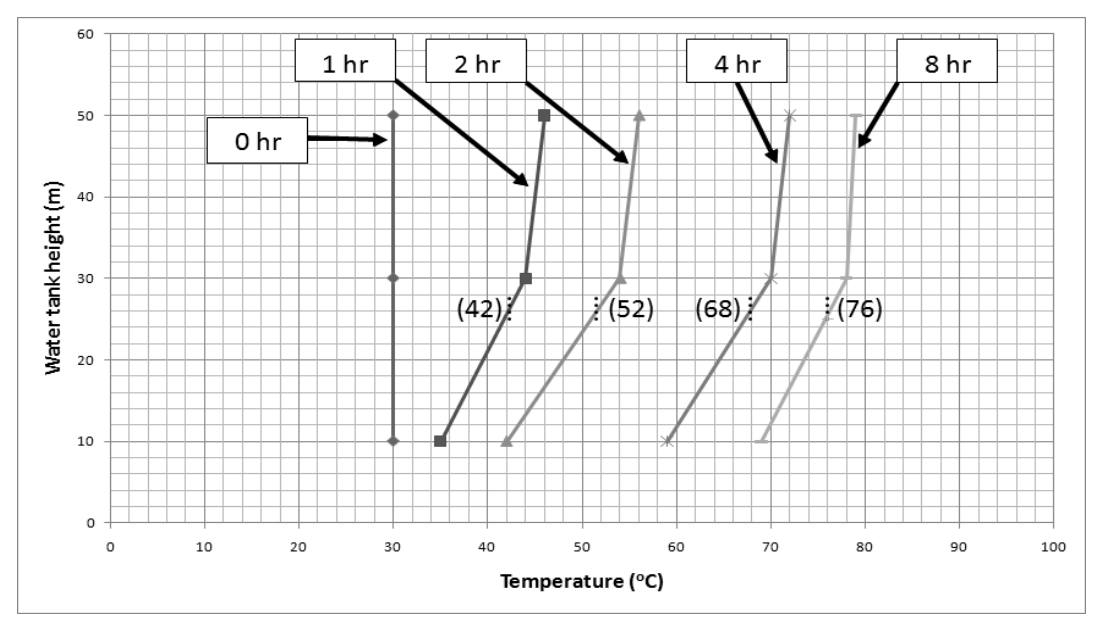

Figure 4. Water temperature distribution inside storage tank 


\subsection{Baseline Case}

A typical p-h diagram for the baseline case at the end of 8 hours of operation is shown in Fig. 5. The refrigerant before and after compression are shown to be superheated and the condensed liquid is sub-cooled. The results also show that there was a temperature drop of about $7^{\circ} \mathrm{C}$ in the discharge line between points 2 and 3. Pressure drop in the refrigerant flow-meter between points 4 and 5 was negligible. A pressure drop of about 1 bar was observed between points 6 and 7 and about 0.8 bar in the evaporator coil between points 7 and 8 . Since outdoor ambient and indoor room temperatures were not controlled, their variation could affect the results to a certain degree. Figure 6 shows the measured compressor power was about $1.0 \mathrm{~kW}$. The ratio of the calculated compressor power from Eq. 3 and the measured compressor power $\left(\gamma_{1}\right)$ varied from $0.9-1.0$ because of compressor power factor. $\mathrm{COP}_{\mathrm{r}}$ for cooling varied from $3.0-4.0 \mathrm{COP}_{\mathrm{h}}$ for heating varied from $4.0-5.0$ as expected.

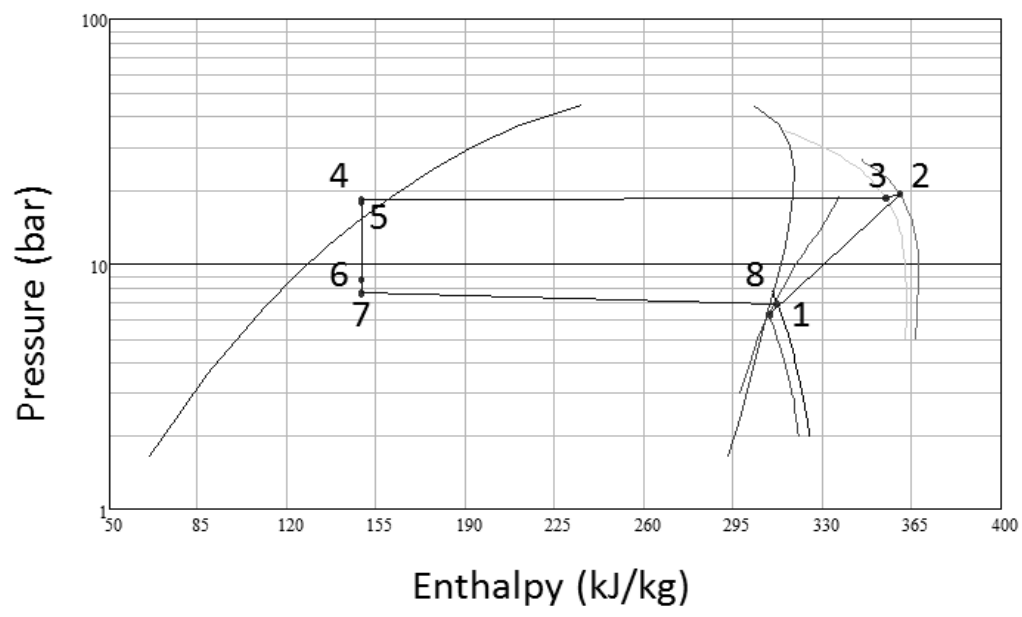

Figure 5. P-h diagram for baseline case after 8 hours

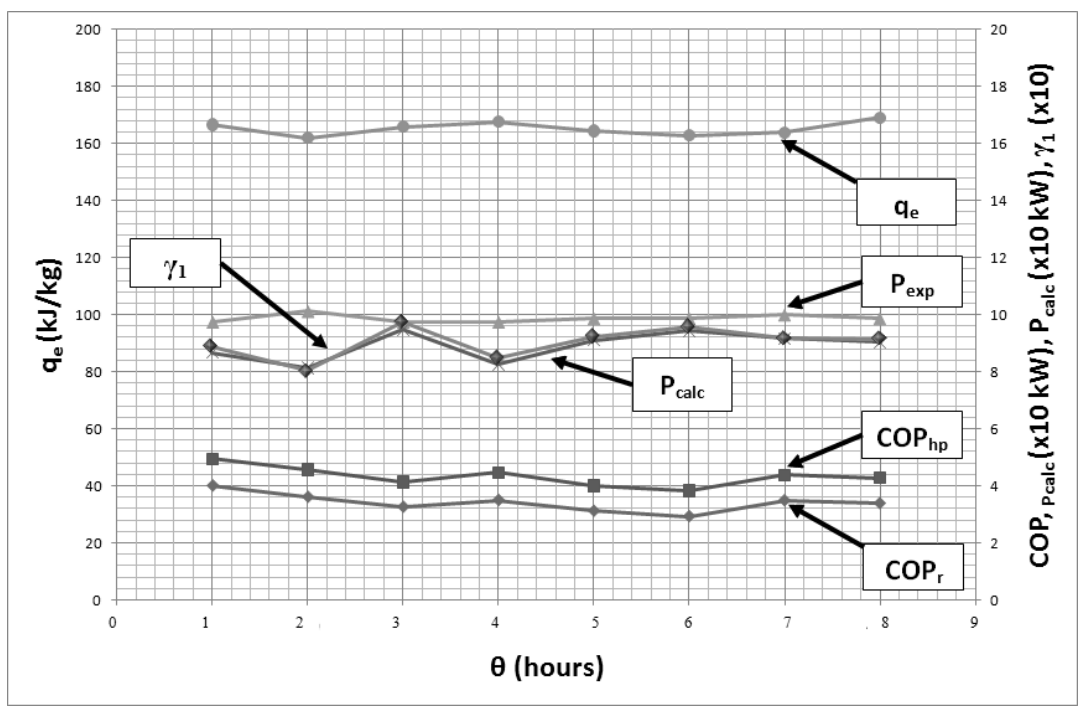

Figure 6. Base-line performance of air conditioning system

\subsection{Heat Reclaim with Internal Coil}

A typical p-h diagram for the heat reclaim case with internal coil at the end of 8 hours of operation is shown in Fig. 7. The refrigerant was desuperheated by the immersed coil but remain superheated at point 3. It was then condensed to a sub-cooled liquid by the air-cooled condenser. There was no noticeable change in compressor 
power, between $0.95-1.0 \mathrm{~kW}$ as was with the base case. Figure 8 shows the mean storage tank water temperature, initially at $30^{\circ} \mathrm{C}$ was heated to $58^{\circ} \mathrm{C}$ after about 3 hours of operation and to $75^{\circ} \mathrm{C}$ after 8 hours. The ratio of heat rejected at the water-cooled condenser/total heat rejected $\left(\gamma_{2}\right)$ varied from 0.15 after 3 hours to 0.09 after 8 hours. Heat rejection ratio decreased as the tank water temperature increased, as expected. $\mathrm{COP}_{\mathrm{r}}$ for cooling varied between $3.1-3.3$.

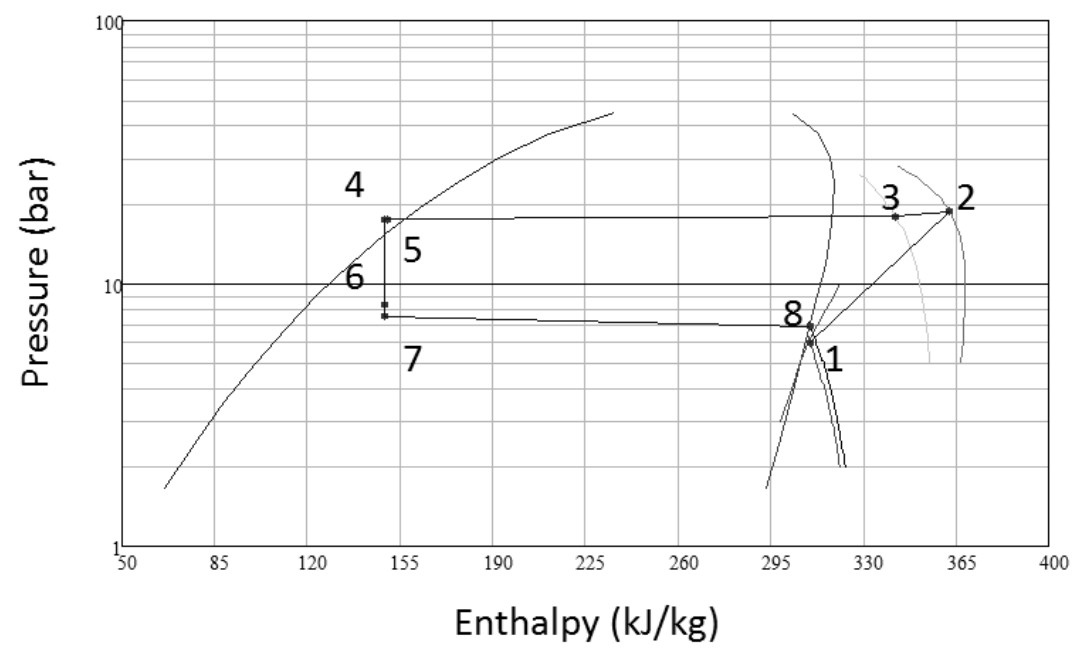

Figure 7. P-h diagram for heat reclaim with internal coils after 8 hours

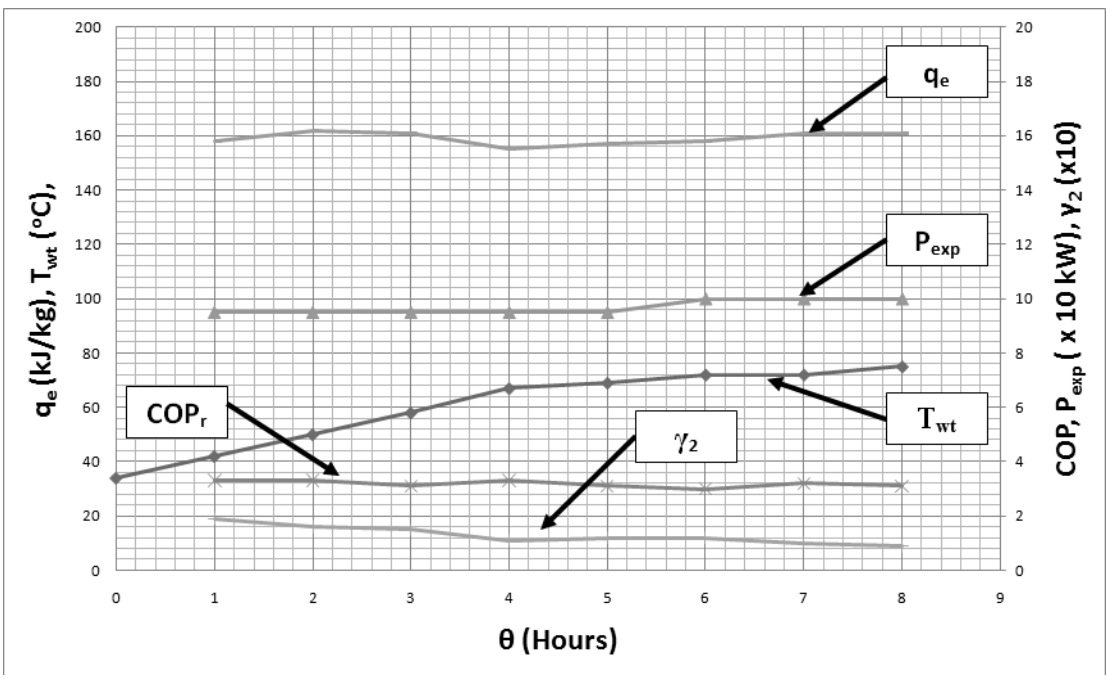

Figure 8. Performance of heat reclaim system with internal coil

\subsection{Heat Reclaim with External Coil}

A typical p-h diagram for the heat reclaim case with external coil at the end of 8 hours of operation is shown in Fig. 9. The amount of desuperheating undergone by the refrigerant in the external coil was small in this case, as compared with the immersed coil. The simple design of merely wrapping the heat exchange coil on the outside of the tank resulted in very poor heat transfer between the coil and the water in the tank. The design could be improved by providing corrugated grooves on the outside of the tank and providing thermal paste. There was also more sub-cooling in this case. Figure 10 shows the mean storage tank water temperature was heated from $29^{\circ} \mathrm{C}$ to $41^{\circ} \mathrm{C}$ after about 8 hours of operation. The ratio of superheat recovered $\left(\gamma_{2}\right)$ was only about 0.08 
throughout. The compressor power was observed to vary between $0.8-0.9 \mathrm{~kW}$ and $\mathrm{COP}_{\mathrm{r}}$ for cooling varied between $3.0-4.0$.

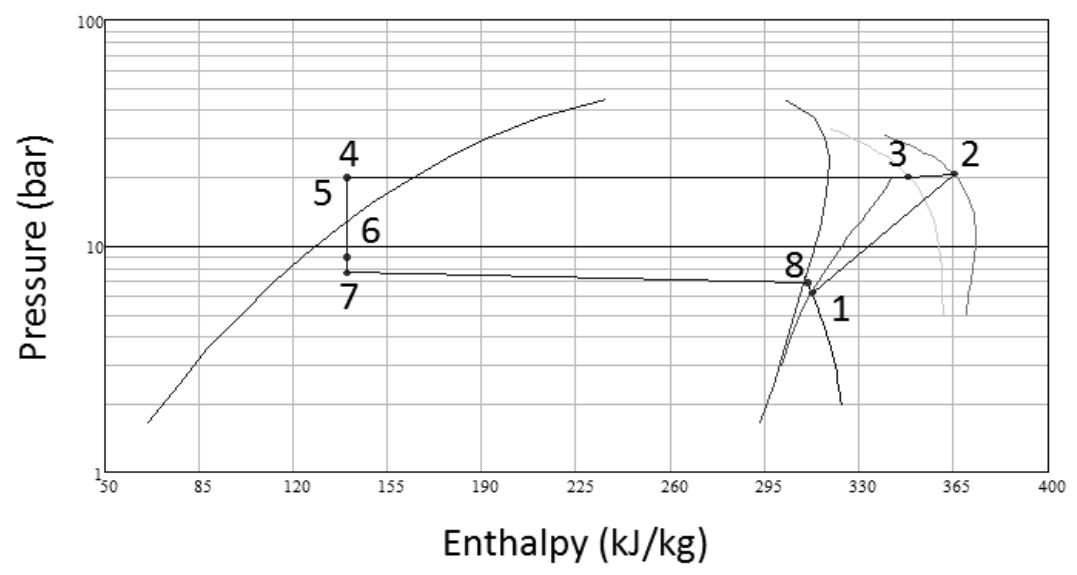

Figure 9. P-h diagram for heat reclaim with external coil after 8 hours

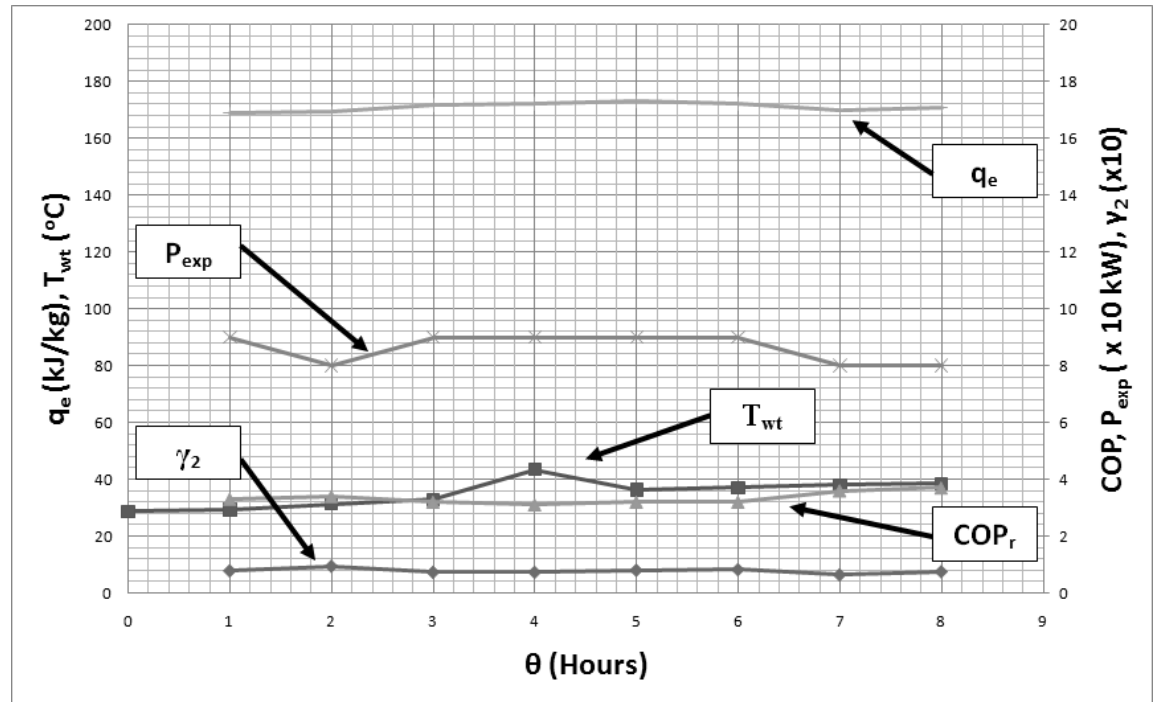

Figure 10. Performance of heat reclaim system with external coil

\subsection{Comparison of Heat Reclaim with Internal and External Coils}

Table 1 compares the performances of the three cases at the end of 8 hours of operation. The values were taken from 2 runs each. Since the room and outdoor ambient conditions were not controlled, slight variations in results are expected especially in the external coil case where the experiments were conducted at different days. In the case with the internal coil, the experiment was conducted during rainy periods and larger variations in the results are observed. For the baseline case, compressor power was measured at $0.99 \mathrm{~kW}$. The compressor power input for the internal coil case was about $1 \mathrm{KW}$. This was because of the extra pressure drop along the immersed coil. The external coil condenser was about $1 \mathrm{~m}$ longer than the immersed coil. The small difference in coil lengths should not make much difference in the compressor power. The low lower compressor power of $0.8 \mathrm{~kW}$ in the external coil case was attributed to the cooler ambient conditions. $\mathrm{COP}_{\mathrm{r}}$ for the internal coil case was lowest at 3.1 compared with 3.3 and 3.5 for the other cases. The internal coil was more efficient in heating the water in the tank as expected. It could heat water up to $75^{\circ} \mathrm{C}$ after 8 hours of operation. The external coil tank had about $70 \%$ more volume than the internal coil tank. Hence the temperature of the water is expected to be lower. However, 
the heat recovery factor $\left(\gamma_{2}\right)$ was lower than the external coil tank. This shows that the internal coil system performed better than the external coil system, as expected. The lengths of the condenser coils in both cases were approximately the same. A longer external coil could perhaps perform a similar heating duty as the internal coil albeit at a higher pressure drop. Refrigerating capacity $\left(\mathrm{q}_{\mathrm{e}}\right)$ was about $161 \mathrm{~kJ} / \mathrm{kg}$ for the internal coil case and around $170 \mathrm{~kJ} / \mathrm{kg}$ for the other cases.

Generally it could be concluded that within the confines of the experiments conducted where ambient condition could not be controlled, there was very little difference in the performances of the three systems in terms of energy savings and cooling capacity. We would expect the baseline case compressor power to be less because of the extra pressure drops encountered in the heat reclaim condensers.

Table 1. Comparison of heat reclaim with internal and external coils after 8 hours

\begin{tabular}{cccccc}
\hline Case & $\mathrm{P}(\mathrm{kW})$ & $\mathrm{T}_{\mathrm{wt}}\left({ }^{\circ} \mathrm{C}\right)$ & $\gamma_{2}$ & $\mathrm{COP}_{\mathrm{r}}$ & $\mathrm{q}_{\mathrm{e}}(\mathrm{kJ} / \mathrm{kg})$ \\
\hline Baseline & 0.99 & - & - & 3.3 & 169 \\
Internal coil & 1.0 & 75 & 0.09 & 3.1 & 161 \\
External coil & $0.80-0.78$ & $38.5-40.5$ & $0.072-0.075$ & $3.7-3.2$ & $172-171$ \\
\hline
\end{tabular}

\section{Conclusions}

An experimental investigation was conducted to determine the performances of an air conditioning system with and without additional water-cooled condensers for heat reclaim. One of the condensers had an internal coil submerged in a hot water storage tank while the other had an external coil wound round the tank. It was found that there was very little difference in the performances of the air conditioning systems with or without the heat reclaim system in terms of energy savings and cooling capacity. The internal coil system was found to be more efficient in heating the water in the tank.

\section{Acknowledgements}

Thanks are extended to Mr. J. S. Gan for compiling the results, Mr. M. W. Wong and Mr. Ian Sta Maria for carrying out the experiments.

\section{References}

Bong, P. E., Hawlader, M. N. A., \& Mahmood, W. (1988). The prospect of incorporating desuperheaters to room air-conditioners for tropical application. ASHRAE Transactions, 94, Part 1, 340-349.

Cook, R. E. (1990). Water storage tank requirements for residential heat pump/air conditioner desuperheater heat recovery. ASHRAE Transaction, 96, Part 2, 715-719.

Hepbasli, A., \& Kalinci, Y. (2009). A review of heat pump water heating systems. Renewable and Sustainable Energy Reviews, 13, 1211-1229. http://dx.doi.org/10.1016/j.rser.2008.08.002

Jie, J., Chow, T. T., Pei, G., \& He, W. (2003). Domestic air-conditioner and integrated water heater for subtropical climate. Applied Thermal Engineering, 23, 581-592. http://dx.doi.org/10.1016/S1359-4311(02) 00228-4

Lee, A. H. W., \& Jones, J. W. (1996). Thermal performance of a residential desuperheater water heater system. Energy Conversion Management, 37, 389-397. http://dx.doi.org/10.1016/0196-8904(95)00195-6

Lee, A. H. W., \& Jones, J. W. (1997). Analytical model of a residential desuperheater. Applied Energy, 57, 271-285. http://dx.doi.org/10.1016/S0306-2619(97)00028-7

Mei, V. C., Chen, F. C., Domitrivic, R., Kilpatrick, J. K., \& Carter, J. A. (2003). A study of a natural convection immersed condenser heat pump water heater. ASHRAE Transactions, 109, 3-8.

Toh, K. C., \& Chan, S. K. (1993). Themosiphon heat recovery from an air conditioner for a domestic hot water system. ASHRAE Transactions, 99, Part 1, 259-264.

Valentine, M. L., \& Goldschmidt, V. W. (1989). Mathematical model of a refrigerant desuperheater for heat recovery. ASHRAE Transactions, 95, Part 1, 215-223. 
Ying, W. M. (1989). Performance of room air conditioner used for cooling and hot water heating. $A S H R A E$ Transactions, 95, Part 1, 441-444.

\section{Nomenclature}

$\mathrm{c}_{\mathrm{p}}$ specific heat $[\mathrm{kJ} / \mathrm{kg} \mathrm{K}]$

$\mathrm{COP}_{\mathrm{h}} \quad$ coefficient of heating

$\mathrm{COP}_{\mathrm{r}} \quad$ coefficient of cooling

$\mathrm{h} \quad$ specific enthalpy $[\mathrm{kJ} / \mathrm{kg}]$

$\mathrm{k}$. thermal conductivity $[\mathrm{kJ} / \mathrm{m} \mathrm{K}]$

$m$ refrigerant mass flowrate $[\mathrm{kg} / \mathrm{s}$ )

$\mathrm{P}$ measured compressor power $[\mathrm{kJ} / \mathrm{s}]$

$\mathrm{P}_{\text {calc }}$ calculated compressor power $[\mathrm{kJ} / \mathrm{s}]$

$q$ heat transfer rate $[\mathrm{kJ} / \mathrm{kg}$ )

$\mathrm{T}_{\mathrm{wt}}$ mean water temperature $\left[{ }^{\circ} \mathrm{C}\right]$

$\theta \quad$ time [s]

$\gamma_{1}$ ratio $\left[\mathrm{P}_{\text {calc }} / \mathrm{P}\right]$

$\gamma_{2} \quad$ ratio $\left[\dot{\mathrm{q}}_{\mathrm{wc}} / \dot{\mathrm{q}}_{\mathrm{t}}\right]$

\section{Suffix}

c condenser

e evaporator

$\mathrm{t}$ total

wc water-cooled condenser 